BULLETIN Bulletin hispanique

HISPANIQUE Université Michel de Montaigne Bordeaux

117-2 | 2015

Métamorphose(s) : représentations et réécritures

\title{
Cuerpos desregulados y angustia lírica
}

en torno a ciertos mitos de metamorfosis en el cancionero garcilasiano

Juan Diego Vila

\section{(2) OpenEdition}

Journals

Edición electrónica

URL: http://journals.openedition.org/bulletinhispanique/3974

DOI: 10.4000/bulletinhispanique.3974

ISSN: 1775-3821

Editor

Presses universitaires de Bordeaux

Edición impresa

Fecha de publicación: 15 diciembre 2015

Paginación: 457-472

ISBN: 979-10-300-0041-2

ISSN: 0007-4640

Referencia electrónica

Juan Diego Vila, «Cuerpos desregulados y angustia lírica », Bulletin hispanique [En línea], 117-2 | 2015,

Publicado el 15 diciembre 2018, consultado el 05 mayo 2019. URL : http://journals.openedition.org/

bulletinhispanique/3974; DOI : 10.4000/bulletinhispanique.3974 


\title{
Cuerpos desregulados y angustia lírica: en torno a ciertos mitos de metamorfosis en el cancionero garcilasiano
}

\author{
Juan Diego Vila \\ Université de Buenos Aires
}

Para Fernando Copello, por su generosa amistad

Le retour aux sonnets mythologiques de Garcilaso XI, XIII et XXIX n'a pas pour but d'invalider leur évidente caractérisation thématique mais de montrer un autre aspect différenciateur : l'incertitude identitaire due aux changements, autant de variations qui manifestent le trauma de l'être dans le temps.

Mots-clés : métamorphose, mythes, sujet lyrique, événement, changement.

El retorno a los sonetos XI, XIII y XXIX mitológicos de Garcilaso no aspira a invalidar esa certeza argumental sino a manifestar otro signo diferenciador: la incertidumbre de la identidad en el crisol de los cambios. Variaciones que refieren el trauma del ser en el tiempo.

Palabras claves: metamorfosis, mitos, sujeto lírico, acontecimiento, cambio.

The return to Garcilaso's mythological sonnets XI, XIII and XXIX does not aim at invalidating their obvious thematic characterization, but rather at showing another differentiating aspect : the identity uncertainty due to changes - as many variations that indicate the being's trauma in time.

Keywords: metamorphosis, myths, lirical subject, event, change. 


\begin{abstract}
$\Delta$ bordar el motivo de la metamorfosis en el corpus lírico garcilasiano A dista de ser cuestión zanjada por las lecturas al uso puesto que los relatos de transformaciones no son simple sinécdoque del universo mítico legado por la cultura grecolatina; y tampoco es posible soslayar que las operaciones críticas en torno a lo mítico en tales o cuales ingenios o, incluso, períodos estéticos, no suelen aportar, con igual grado, lecturas o interpretaciones que focalicen la singularidad y especificidad de los textos en que tales reelaboraciones o reescrituras cultas se constatan.
\end{abstract}

En efecto, los análisis de las míticas metamorfosis que pueblan tantas obras parecen estar condicionados por protocolos de análisis e interpretación, en lo que al mito respecta, que condicionan, de antemano, la entidad del motivo bajo análisis.

Y no es temerario sostener que el tratamiento tributado al toledano no es excepción del conjunto por cuanto prima cierta inercia crítica que reconduce las interpretaciones de especialistas al sereno universo de la tautología. Desde allí todo principio de indeterminación propio del tipo discursivo " mito » resultará anulado y se obrará el prodigio impensado: la fragua de un significante castrado en su significancia. Ya que si todo mito es habla monstruosa que diría, cual alegoría furiosa, siempre más de lo que parece afirmar, necesario se vuelve que su frecuentación e intelección comunitaria se opere desde el aplanamiento y reducción de todo excedente sémico.

Proceso exegético que subvierte de plano la entidad de los constituyentes distinguidos por Marcel Detienne al definir al mito como el lugar semántico de un cruce e hibridación de dos discursos, de los cuales el primero refiere una anécdota mientras que el segundo se constituye desde la voluntad de hablar y decir, volviendo sobre sí mismo, una interpretación ${ }^{1}$. De lo cual podemos colegir que la faz mítica usualmente declarada por ediciones críticas y estudios de especialistas termina revelándose como un universo mudo y domesticado de dioses, figuras intermediarias y humanos que interactuaron entre sí.

Pues, según parece, las condiciones de inteligibilidad de lo mítico dependen de un régimen escópico muy particular, según el cual el requisito básico de acceso a ese confín otro en que el discurso del autor se funde con hablas inmemoriales es el ejercicio de una lectura fragmentada, ya que lo extraño resulta amigable en tanto y en cuanto se garantiza el silenciamiento, en sabio fuera de foco, de todo aquello que incomoda o perturba la ejemplar majestad deseada.

Esta dinámica de silencios y voces, de luces y sombras exegéticas en materia mítica en Garcilaso puede testimoniarse desde variados ángulos, muchos de los cuales resultan tributarios de los abordajes que formularon los primeros anotadores ${ }^{2}$ y ello explica por qué para un amplio sector de la crítica contemporánea el trabajo con los mitos puede considerarse realizado desde la

1. Marcel Detienne, La invención de la mitología, Barcelona, Seix-Barral, 1982.

2. Véase Carmen Codoñer Merino, "Comentaristas de Garcilaso ", en Víctor García de la Concha (ed.), Academia Literaria Renacentista. IV Garcilaso, Salamanca, Ediciones Universidad de Salamanca, 1986, p. 185-200. 
parquedad y sobriedad comunicativa propia de las notas en las ediciones críticas, trazo en el cual la identificación, la filiación textual y el trazado de equivalencias clarificadoras debería considerarse como apto e idóneo para sustituir la reflexión conceptual sobre los contenidos comunicados por la fábula.

Lo cual bien se comprende porque desde el Brocense y Fernando de Herrera se aborda la declaración de los mitos desde una práctica totalmente paradójica: se explicita la urgencia de su identificación y, a renglón seguido, se manifiesta la conveniencia de todo silencio a su respecto:

B.14: En el soneto XII toca la fábula de Ícaro y de Faetón, que por ser vulgares no las cuento ${ }^{3}$.

H.267: Anaxárete. Por ser muy vulgar esta fábula, y tratalla largamente Ovidio en el 14, y don Diego de Mendoza en coplas españolas, dejo de referilla; sólo apuntaré los lugares que tocaren Ovidio y don Diego de su transformación para que se pueda hacer conferencia con $\mathrm{GL}^{4}$.

A diferencia de otro tipo de lugares iluminados, los mitos oficiarían de signo revelador de la comunidad de cultura que debería existir entre autor, anotador y público 5 . Y este es el motivo por el que no puede soslayarse el imperativo de economía simbólica que regula estos reencuentros comunicativos dado que cuando cada anotador advierte que alguna figura legendaria puede ser ignorada no vacila en incorporar un argumento a su respecto. Ahora bien, la dimensión argumental de los mitos debe ser considerada desde dos ángulos de análisis bien diversos.

En primer lugar aquel que pauta cómo el argumento funciona, usualmente, como sinécdoque de un todo:

B.56: Hágate temerosa el caso de Anaxárte y cobarde. Esta fábula cuenta largamente Ovidio, libr. 14. En suma es que Yphis andaba muy enamorado de Anaxárte y no pudiéndola enternecer a sus plegarias, amanecióle un día ahorcado a la puerta. Y ella como le vio, quedóse helada y fue vuelta en mármol ${ }^{6}$.

El Brocense cree satisfacer la declaración del mito obrando una síntesis argumental pero esta revelación anecdótica supone, a su vez, el ocultamiento certero de lo que podría interpretarse a este respecto. Los lectores no tienen por qué inquietarse ante la mutación de una doncella en mármol por cuanto el argumento afianza el efecto de irrealidad consensuada y aceptada por todos ${ }^{7}$.

3. Antonio Gallego Morell, Garcilaso de la Vega y sus comentaristas. Obras completas del poeta acompañadas de los textos integros de los comentarios de El Brocense, Fernando de Herrera, Tamayo de Vargas y Azara, Madrid, Editorial Gredos 2a ed. revisada y adicionada, 1972, p. 268. Los comentaristas de Garcilaso se citan siempre por esta edición, de aquí en más Comentaristas, indicándose a continuación la página. Para el distingo del anotador ha de estarse atento a que cada uno de ellos aparece declarado por la letra inicial previa al número de nota. Así B, es el Brocense, H, Fernando de Herrera, T, Tamayo de Vargas y A, Azara.

4. Comentaristas, p. 412.

5. Ver, al respecto, José Antonio Maravall, Antiguos y Modernos, Madrid, Alianza editorial, 1998, p. 281-322 y 323-360.

6. Comentaristas, p. 275.

7. Abordé la problemática de la progresiva habituación lectora ante los mitos clásicos en «En 
Pero también es central advertir que el trabajo crítico sobre los argumentos se ve determinado por imperativos contextuales que apuntan al uso y el consumo de estas fábulas. El Brocense declara, respecto de Yphis y Anaxárate (B.56), aquello que ańos más tarde ruborizará a Herrera mencionar (H.267). Y si bien es cierto que la memoria de los mitos -en ese eje cronológico- podría apuntalar la ilusio de progreso cognoscitivo, no debe pasarse por alto, con todo, que nuestro erudito sevillano hace gala, en sus notas, de una floración argumental variada respecto de las narraciones más conocidas.

Los argumentos míticos se encuentran organizados en inestable eje polar que se tensa, a nivel formal, entre el silencio y la sobredeterminación de alternativas, y, a nivel emotivo, entre la vergüenza y la fruición vanidosa del acto de distinción perpetrado por la propia pluma. E importa señalar esta pasión que organiza la cartografía herreriana de la lírica de Garcilaso por cuanto es testimonio inequívoco de cómo, en el pasaje de la pura oralidad significante a la escritura memoriosa, el mito deviene opinable patrimonio de autor ${ }^{8}$. Y refuerza el supuesto de que lo declarado es, en todo momento y en toda su extensión, la emergencia demorada del segundo discurso distinguido por Detienne, el habla de la interpretación, esa relación aplazada y apenas intuida por el vulgo de una lógica otra que volvería significante la sinrazón significada por la fábula.

No se me escapa que el modelo de anotación herreriana abreva en una matriz compartida por los manuales mitográficos renacentistas cual sería la reducción de los sentidos posibles de los mitos a lecciones históricas, morales, espirituales o seudo científicas conforme lo analiza Jean Seznec en magistral estudio?. Pero que la cultura de determinadas comunidades se brinde a sí misma protocolos de lectura unívocos de la mitología no garantiza que sean esos sentidos los que regulan la voluntad significante de una mención mítica en algún poema. Antes bien cabe señalar que ese exceso discursivo opaca una verdadera ausencia, la de un discurso orgánico que interprete la razón de ser de esta hibridación mítica del texto indagado ${ }^{10}$.

torno a la múltiple constitución del discurso mitológico en el Siglo de Oro Español », Argos (Buenos Aires), 13-14, 1989-1990, p. 147-183.

8. Este es uno de los mayores problemas que enfrenta toda crítica interesada en la reescritura de los mitos clásicos pues suele ser un gesto muy habitual considerar que este enfoque se agota en la posibilidad de fijar tal o cual "antecedente" como modelo del pasaje iluminado. No sólo es opinable porque ligan la ideación de un mito a las versiones escritas conservadas de la antigüedad, sino que también resultan censurables porque desatienden la posibilidad material de que tales versiones -en sus lenguas originales o versiones romanceadas- hubiesen estado al alcance de los eruditos del período trabajado. Para no incurrir en este fallo, imprescindible es el volumen de Theodore S. Beardsley, Hispano Classical translations printed between 1482 and 1699, Pittsburg, Pennsylvania, Duquesne University Press, Louvain, ed. E. Nawelaerts, 1970.

9. Jean Seznec, La survivance des dieux antiques. Essai sur le rôle de la tradition mythologique dans lhumanisme et dans lart de la Renaissance, Paris, Flammarion, 1980.

10. Puede recordarse, al respecto, que este anhelo ya estaba presente en el seminal trabajo de María Rosa Lida titulado «Transmisión y recreación de temas grecolatinos en la poesía lírica 
Recordemos que este reparo sobre el valor exegético de los discursos de las anotaciones no es absoluto puesto que también se constatan pareceres más coherentes, subjetivos y organizados sobre el valor de estas fábulas, aunque es digna de mención una disposición quiasmática bien sugestiva. Las piezas que la crítica tipificó como " mitológicas " -basándose en un criterio eminentemente argumental o sustantivo pues la materia del texto es una anécdota mítica referida- son aquellas que resultan sometidas a la mayor torsión mitográfica, brindándosenos, en ocasiones, el sucedáneo de una interpretación faltante. Mientras que aquellas en que lo mítico se reduce a simples equivalencias o correlatos metafóricos del sujeto lírico, poseen, como sería el caso del Soneto XII, lecturas más próximas a lo que podría entenderse como discurso significante del mito evocado.

Todo lo cual nos permite remarcar que el discurso segundo sólo se vuelve evidente cuando hay un sujeto que refiere el tipo de interpelación que produce la dimensión evocativa del mito. Lo cual explica que esta hexis haya resultado desatendida por la posteridad tan preocupada por legar una ciencia objetiva de lo literario.

Este punto de partida es lo que explica por qué, en los estudios del último siglo sobre la obra de Garcilaso, la mitología clásica y sus consabidas metamorfosis resultan recuperadas si, sugestivamente, se legitima un desplazamiento epistémico bien notorio consistente en sostener que las menciones míticas son siempre prueba o testimonio de algo diverso y distinto de lo que podría conjeturarse como vertiente mítica de su poética.

Así pueden ser la cabal certificación de una educación esmerada propia de los cortesanos, ejemplo de su casi segura habituación con originales clásicos antes que con traducciones romances de textos de la antigüedad grecolatina, y clave para entender la apropiación creativa del esplendor cultural italiano pletórico en formas y motivos neoclásicos. Pero nunca indicio inequívoco de que así como la mitología podía atraerlo e inspirarlo que esos mitos de transformaciones suponían una disquisición poética y concreción tópica de una problemática sustantiva de su lirismo: el cambio ${ }^{11}$.

No se trata aquí de invalidar con criterio positivista todo aquello de lo cual no hay documentación fidedigna ni de impugnar asertos que bien se podrían compartir sino de iluminar el preconcepto imperante respecto de lo mítico.

española ", Filología, I, 1939, p. 20-63, ulteriormente recogido en el volumen La tradición clásica en España, Barcelona, Ariel, 1975, p. 37-38.

11. Hoy día inexcusables, a este respecto, se vuelven los diversos abordajes que se han ido conociendo de la tesis doctoral de Florence Madelpuech, L'écriture du temps dans les "Églogas" et les "Elegías" de Garcilaso de la Vega, dirigida por Jean-Pierre Étienvre y aún inédita. Distintos adelantos pueden conocerse bajo la forma de artículos o capítulos de libros. Destaco « la inmediatez paradójica o la relación amorosa imposible en las Églogas de Garcilaso de la Vega ", Criticón, 97-98, 2006, p. 123-136 y "Revisión de una escritura canónica y aproximación a una poética original: La temporalidad en Garcilaso de la Vega ", en Pedro Ruiz Pérez, Cánones críticos en la poesía de los Siglos de Oro, Vigo, Academia del Hispanismo, 2008, p. 75-85. 
Fenómeno que siempre podría probar otras lecturas, pero jamás suscitar la necesidad de una puesta en valor otra de su propia entidad en el interior del sistema. Y creo no andar errado si reputo que las limitaciones señaladas tuvieron su origen en la aporía categorial que supuso, para muchos, edificar a propósito de Garcilaso, el modelo de claridad, equilibrio y raciocinio estético renacentista integrando la irracionalidad del mito.

Por ello no asombra que muchas de las revalorizaciones de tales o cuales mitos en Garcilaso se hayan materializado en abordajes que no lo tenían como objeto de estudio central sino como estadio cuasi liminar del itinerario de un motivo mítico en las letras espańolas ${ }^{12}$.

Y es por demás sintomático que en esta tensión crítica en torno a lo mítico en Garcilaso, el único estudio sistemático de valor sobre esta problemática pueda ser emplazado en el fiel que dividiría la preeminencia de intereses críticos opuestos. En efecto, el estudio de Guillou-Varga comparte con los abordajes de itinerario mítico una ampliación del campo usualmente restringido a un autor: su tesis no se focaliza exclusivamente en Garcilaso, sino en un eje al que se suma a Herrera y a Góngora ${ }^{13}$.

Pero, a mi humilde entender, ejemplifica a la perfección el aserto de que las respuestas textuales penden del tipo de interpelación que el crítico ha formulado. Pues allende el notorio trabajo que la autora se ha tomado en perspectiva bien exhaustiva, no puede ignorarse que muchas de sus conclusiones han sido formuladas en función de una criba de sentido evidente: la afiliación de las metáforas o presencias míticas a algunos de los órdenes imaginarios diagramados por Bachelard. Lo cual nos autoriza a sostener que si bien puede considerarse muy bien probada la afiliación de Garcilaso al universo simbólico del agua, y allí hay páginas bien iluminadoras ${ }^{14}$, no puede pasarse por alto que fueron el resultado de una focalización muy otra: la posibilidad de predicar

12. La mayoría de estos abordajes críticos pueden esquematizarse en la titulación básica "El mito de X en la literatura española ». En un amplio conjunto de estos trabajos prima un desinterés notorio por la totalidad de la composición poética u obra de autor en que estas reelaboraciones ocurren, por cuanto lo que prima es el interés por la reformulación de ciertos motivos míticos, ya de un modo integral, ya a partir de detalles evocativos. E innecesario es precisar que estas propuestas no se centran en producir una interpretación mitológica sobre el sentido de tal hibridación pues se contentan con precisar aspectos de estilo pero no polémicas de sentido. El punto clave sería que muchos indagan sobre la funcionalidad sin advertir que se conforman con el nivel « oracional » de las menciones míticas y olvidan la inclusión del pasaje en una lógica "textual" muy otra. Lo cual facilita las taxonomías funcionales.

13. Suzanne Guillou-Varga, Mythes, mythographies et poésie lyrique au Siècle d'Or espagnol, Paris, Didier Érudition, 1986.

14. "Ces divinités, loin d'être les résurgences académiques ou automatiques d'une culture antique figée, apparaissent sous un tour nouveau, revivifiées à la faveur de métamorphoses où l'eau joue un rôle fondamental» (Suzanne Guillou-Varga, op. cit., p. 367); « l'eau chez Garcilaso est avant tout un appel essentiel, celui de la substance de ses rêveries » (Ibid., p. 368); « Le lecteur de Garcilaso comprendra ainsi que l'eau correspond chez celui-ci à un "type de destin, [...] un destin essentiel” " (Ibid.). 
cómo muchos de los trabajos con mitos en los tres líricos pendían de este estado de pertenencia imaginaria en la faz creativa del sujeto autorial a alguno de los órdenes señalados, ya el agua, ya el fuego, ya el aire.

El corpus lírico que recorto para mi indagación depende de la experiencia de lectura del Cancionero de Garcilaso ${ }^{15}$, y para ello me centro en tres sonetos: el XI, el XIII y el XXIX. La atención a ellos depende de una variable que los diferencia de todas las otras composiciones en que se pueden constatar menciones míticas, ya que se distinguen por emplazar la voz lírica ante la experiencia de reflexionar sobre el cambio -producido, posible o en proceso- a propósito de una interacción con figuras típicas del imaginario mítico-legendario. Tal es así que podría predicarse que lo que muchos han caracterizado como mitos explícitos son asedios a metamorfosis. Lo que nos permite sostener que la oposición explícito-implícito puede reformularse como textos con metamorfosis (míticas) y composiciones con simples menciones o alusiones sobre figuras míticas.

Que el todo -lo mítico- resulte desenfocado en beneficio de la parte -las metamorfosis- emplaza al lector a reconsiderar las razones por las cuales la voz poética del Cancionero construye un horizonte en el que las figuras míticas pueden ser, a través de metáforas o declaraciones nominales expresas, puntos de referencia del horizonte habitual de la propia existencia mientras que las metamorfosis de ciertas figuras se erigen como el escándalo lírico que reclama la atención del ojo lector.

Leídas desde este ángulo cabe señalar que lo que introducen estas narraciones de metamorfosis es, primordialmente, todo cuanto puede predicarse como corolario lógico de la caída del sujeto de un mundo ideal emplazado fuera del tiempo. Pérdida que emplaza a la voz lírica ante la tortuosa experiencia de la diferenciación en tanto individuación sin garantía de homogeneidad con el entorno. Porque el cambio que liberan estas transformaciones referidas forja la distancia, la separación del individuo y la certeza de que el cambio ha de ser experimentado en crisis pues si, para Occidente, la condición de predicación de una identidad es la corroboración de una permanencia, lógico es que-como Gilson lo señalara- se perciba al cambio como un escándalo ontológico: aquello que, poniendo a prueba el ser de las cosas, la posibilidad de seguir predicando que ellas son, interpela, en el espectáculo de la mutación, al sujeto que observa y se cree exento y a resguardo de tal alteración. ¿Cómo ser y cómo existir en un mundo en el que el cambio existe si la condición básica para saberme existente es permanecer?

Un segundo detalle que distingue a estos sonetos de metamorfosis es que todos se ofrecen como minúsculas viñetas dramáticas en las que la focalización

15. Experiencia de lectura que no habría sido tal de no haber mediado el finísimo, fundacional y estrictamente documentado análisis de Nadine Ly " Garcilaso : une autre trajectoire poétique ", Bulletin Hispanique, LXXXIII, 3-4, juillet-décembre, 1981, p. 263-329. 
de ciertos protagonistas que interactúan o resultan auscultados de modo privilegiado por el poeta, no descarta la recuperación, en sugerente fuera de foco, de otros tantos actores del drama.

Pues si la ilusión binaria y polar pautada por el diálogo del poeta con las ninfas del Soneto XI se quiebra en los últimos versos con el simple recuerdo de que el malestar en el "aquí »" (v. 13) elocutivo es producido por la ausencia de consuelo -con lo cual la enamorada resulta sugerida como no persona, como el nadie dispuesto a calmar la angustia del sujeto-, en el Soneto XIII es necesario destacar que la agonía de Dafne mutando en laurel ante Apolo existe porque hay un ojo lírico que proclama "vi » (v. 3).

Mientras que, en el Soneto XXIX, el caso de Leandro luchando denodadamente por llegar donde Hero se puede pensar como existente y efectivamente acaecido, porque la enunciación se arroga la posición omnisciente de haber estado presente durante el nado oyendo el tenor de las súplicas a las olas en posición que ha de entenderse como la cabal penetración de la interioridad. Pues si los sentimientos de Hero se nos refieren por sus dichos en los versos 12-14 del soneto, el narrador puede legarnos como sentían las olas precisando que «nunca fue su voz de ellas oída » (v. 11).

Los tres sonetos expresan una migración imperceptible de la voz poética pues si el XI se construye como experiencia personal que lo involucra en el suplicio de no ser comprendido a menos que " convertido en agua aquí llorando " (v. 13) se avenga a su propia disolución para encontrar una escucha que lo sosiegue en el allá acuoso donde moran las ninfas, el XIII y el XXIX lo encuentran como testigo de un drama erótico aunque con matices diversos.

En efecto, todo aquello que su visión le ofrece en el XIII parece estar en perfecta sintonía con la rémora de la propia corporeidad delatada en ese ejercicio impúdico de la visión, pues ante un cuerpo que resiste su desaparición del texto, lógico se volvería que todo lo contemplado sean los accidentes externos de la mutación y el espectáculo desolado del padecimiento del enamorado.

En tanto que el Soneto XXIX nos ofrece el prodigio impensado de la lectura de la interioridad explicitando la deriva del ojo al oído. Pues la voz poética puede certificar el portento de olas humanizadas, con voluntad, raciocinio y emotividad suficiente como para oír súplicas y decidir en consecuencia, a cambio de desfigurarse, de un modo cabal, de toda la composición.

Y subsiste además un tercer punto en común insoslayable entre las tres composiciones: el hecho de que todas abordan el motivo de la transformación desde una dinámica intergenérica en la cual el amor -rechazado o correspondido- desencadena la alteración última de la identidad de alguno de los dos enamorados. Por obvio que este detalle nos resulte no se debe desatender que se está en presencia de un subtipo diverso de aquel que forja la lógica del cambio en tanto castigo de una desmesura humana.

16. Garcilaso de la Vega, Obra completa, ed. de Alfonso Sotelo Salas, Madrid, Editora Nacional, 1976. Todas las citas de Garcilaso se harán por esta edición indicándose, en cada caso, los versos entre paréntesis. El soneto XI resulta editado en la página 78, el XIII en las 81-82 y el XXIX en las 111-112. 
Y ello cuenta porque permite reinscribir, sobre el motivo de la no correspondencia erótica -central en dos de las tres composiciones-, la dinámica de culpa y castigo que organiza, muy habitualmente, la alteración radical de un ser en otra cosa: doncellas que devienen aves, enamorados que mutan en astros, personajes que desde la faz vegetal, animal o mineral, obran el recuerdo del quiebre mágico de un linde aleatorio, impredecible e inestable, el que se yergue entre la vida y la muerte de todos.

A lo cual cabe agregar que como es potestad de los olímpicos el estar, por definición, apartados de la muerte, es en ellos en quien recae la posibilidad de obrar el recordatorio del caso significando la muerte en un nacimiento a nuevo orden. Puebla el acervo de la mitología un sinfín de situaciones en que la contraparte humana de las aventuras divinas resulta perpetuada por los dioses -en tensión irresuelta entre el amor y el odio inacabable- en algo inhumano.

$\mathrm{Y}$ es significativo destacar cómo esta mengua de la propia humanidad devenidos seres sin vida racional o volitiva- refracta, como espejo sombrío, la radical diferencia de los hombres ante los dioses, el hecho de que éstos resulten presentados en las narraciones como aptos e idóneos para mutar en lo que se les ocurra, mientras que el hombre se encuentra constreńido a existir como humano.

Este descubrimiento de la limitación implica asumir que todo cambio no debe ser exclusivamente medido en función del después sino, precisamente, en virtud de un sabio contrapunto entre el antes y el más tarde. Y nos conmina a reflexionar si lo que escandaliza del cambio es el prodigio de la mutación en sí misma o, antes bien, la defección de la estabilidad, la imposible perpetuación, la fallida sustracción perfecta de un devenir que funda la individuación y el linde mágico y único de cada cual.

Que las mutaciones analizadas no respondan, unívocamente, al subtipo de la desmesura mítica le confiere al conjunto un plus significante bien diverso puesto que permite el modelado de dos tipos de sujetos líricos distintos. Ya que si las metamorfosis de crimen y castigo predican la entidad del nuevo ser en función del disciplinamiento impuesto por un tercero -habitualmente la divinidad que los constrińe y limita a una nueva e inferior condición respecto de lo humano-, aquellas que trasladan el drama de la conversión de los legendarios individuos al plano de la voluntad del mismo mutante nos permiten inferir la desconfianza lírica ante las aporías de la libertad.

Quien abrasa la propia mutación despliega la soberanía resultante de un ejercicio de autonomía, pero es también quien se sabe en un mundo diverso de aquel donde prima el determinismo de un fatum que lo sustrae de la carga y disyuntiva interna de hacerse cargo de sí, en un universo en el cual lo deseado por cada uno se ve limitado de hecho, pero no de derecho, por lo que el otro, a su turno, quiere ${ }^{17}$. De donde se sigue que las metamorfosis por castigo recortan,

17. Tzvetan Todorov, El jardín imperfecto. Luces y sombras del pensamiento humanista, Barcelona, Paidós, 1998. 
con justicia distributiva, un universo propio del deber ser mientras que las de los mutantes voluntarios se abren a la angustia de lo posible. Ese insondable universo de libres voluntades en el que toda seguridad puede ser caso efímero y probable desilusión.

Y esto es central retenerlo, porque uno de los ejes de sentido que se puede construir a lo largo de los tres sonetos, como compases poéticos diversos de una misma isotopía, es el del drama de la libertad ante la certeza de que la propia voluntad no puede regir ni certificar al otro porque todo contacto con él puede desencadenar, casi inexorablemente, una transformación sobre cuyas consecuencias no hay certeza alguna.

Dado que la posibilidad de percibir al otro como alguien diverso y escindido de sí mismo labra las condiciones de posibilidad para el acceso a la autoconciencia de sujeto castrado, carente, por definición, de la imaginaria totalidad, y posibilita la ilusión - no certificada pero sí imaginada- de que esa merma originaria puede repararse desde la decisión interna de zanjar la distancia que media entre cada cual.

Que los tres sonetos señalados pinten esta tensión de identidades en suplicio, conforme cada cual se aproxime o se aleje, es algo que, difícilmente, se pueda soslayar. El Soneto XI es el que mejor describe la contraposición polar entre la autoconciencia de la propia defección del sujeto lírico y el idealizado registro del otro que, como totalidad autosuficiente, aparece delimitado -desde el apóstrofe de la composición "Hermosas ninfas " (v. 1) - como colectivo plural en el que la fusión imaginaria y prodigiosa se ha logrado.

Pues si éstas resultan percibidas « unas con otras » (v. 7), lo propio de quien se conduele de sí mismo es el aislamiento y la soledad amén de la certeza de que en ese su mundo vaciado de detalles no hay un otro que lo libere de esa marginación figurada por la sugerencia de que se habla desde la ribera deficitaria. "En el río metidas " (v. 1) las ninfas gozan de un mundo en el que la fusión perfecta con la propia naturaleza parece certificada por la descripción de un universo en el que las « columnas de vidrio » (v. 4) y el brillo de sus « moradas " (v. 2) corroboran la suposición de que nada obsta a la percepción de cómo ellas y el propio entorno se encuentran perfectamente fundidas pues la conjunción de luz y transparencia parece ser la clave de ese mundo añorado al que, como cifra distante, se habla desde el dolor.

$\mathrm{Y}$ aquí importa remarcar dos propiedades distintivas que se predican de las ninfas. En primer lugar su hermosura, valor que se entendía fundado, taxativamente, en la virtud de -según Covarrubias- la forma exacta: "Latine FORMOSUS, a forma; Dícese de todo aquello que en sí tiene tal compostura y agrado que deleita con su visión y lleva tras sí nuestro ánimo y voluntad ${ }^{18}$.

18. Sebastián de Covarrubias Orozco, Tesoro de la lengua castellana o española, ed. de Felipe R. Maldonado, revisada por Manuel Camarero, Madrid, Castalia, col. « Nueva Biblioteca de Erudición y Crítica », 1996. Hermoso, p. 629. 
Que las ninfas sean predicadas como "Hermosas " (v. 1) nos mueve a apuntar que cuenta tanto el señalamiento de un efecto causado y producido en la interioridad del sujeto lírico que canta como el detalle de que se reputa a estas deidades intermediarias como dotadas de cuerpo y forma. Esta determinación de las alocutarias líricas en función del absoluto abstracto de la hermosura libera un juego sémico bien sugestivo. No sólo porque se logra predicar una belleza perfecta sin entrar en el detalle de los accidentes particulares sino también porque esa concreción absoluta habilita el discernimiento contextual de otros cuerpos, semejantes y diferentes, de aquellos que se cantan: muy probablemente el cuerpo de una enamorada tan semejante a las mismas ninfas $y$, con toda seguridad, la nefanda materialidad del cuerpo del enamorado que canta.

Por cuanto la efusividad lírica, figurada en ese llanto sin medida que amenaza la integridad del individuo, sugiere que la progresiva aniquilación corpórea con toda probabilidad genere una pasión opuesta a la hermosura. Ya que como cuerpo que espanta conjetura que al alzar "vuestras rubias cabezas a mirarme " (v. 10), el efecto necesario sea el desvío de la mirada.

Mas la hermosura no es el único patrimonio excluyente del otro, sino que también se señala la capacidad de existir en un tiempo fuera del tiempo en el que la identidad absoluta de unas con otras ninfas construye el imperio de la mismidad mientras que la margen del río desde donde se canta marca, desde la diferencia, la angustia del tiempo del dolor. Lo cual explica que la exhortación implorada (" dejad un rato la labor » v. 9) suponga la interrupción de una continuidad sin diferencias. Ya que para que la cronología del padecer quiebre las armónicas y luminosas aguas de las ninfas es menester que éstas se avengan a experimentar el tormento del tiempo fundado en el desamor.

De lo que se infiere que las condiciones expresadas en el último terceto tienen por cometido la certificación de la angustia por la imposible fusión. Pues si tal como está no podrá ser oído por la "lástima » (v. 12) que causa, la idealización que trasunta la propia metamorfosis en pura agua devela que el requisito advertido para obtener consuelo sólo puede ser dicho como especulación porque, de ser real, ya no habría cuerpo que sustente este canto. Torsión final del soneto que, en su aparente claridad, se metamorfosea para cantar, antes que el feliz diálogo consumado, la incomunicación ante el pánico que suscita la diferencia (" no podréis de lástima escucharme ») y la angustia por la transformación identitaria que se regula desde cada encuentro con un otro: convertirse en " agua» (v. 13).

En este eje de lectura el Soneto XIII ejemplifica, a través del mítico agón de Apolo y Dafne, lo que podría tipificarse como el estadio subsiguiente de la gramática vincular entrevista en el XI. Pero su enunciación es viable en tanto y en cuanto la disolución lírica no ha ocurrido y se mienta lo que sería el escańo seguro del próximo estado a través de tópica fabulación devenida en sabio exemplo vitando. Para ello el contenido argumental del mito clásico 
ha sido sometido a particular taracea, operación retórica que nos permite considerar que, incluso en el plano de los contenidos a cantar, es este un soneto de mutaciones.

En primer término porque lo que gana el texto, a partir del borrado de las voluntades de los contendientes, es la posibilidad de diagramar una composición en la cual todo se concentre en el vértigo de las sustituciones. Y, en segundo lugar, porque la focalización del portento de la transformación de la figura femenina en laurel encubre una metamorfosis tanto o más sustantiva que es la del desplazamiento del punto de enunciación lírico testimoniable en el diverso hermanamiento del yo lírico del Soneto XI con el lacrimoso Apolo figurado en el «Aquel » (v. 9) que abre el pliegue conceptual y reflexivo de los tercetos al interior de la composición.

Pero como los cuerpos que se metamorfosean parecen desregulados e inestables cabe señalar que si el llorar obra la aniquilación del sujeto, posible se vuelve considerar que el texto que se cree estable y seguro no sea tal y estemos, entonces, ante una tercera mutación. En efecto, si la contraposición entre cuartetos y tercetos parece bien fundada desde lo argumental como la de dos espectáculos contrapuestos -el de Dafne mutando en laurel en los primeros ocho versos y el de Apolo aumentando su mal, por medio del llanto, en los últimos seis-, merece destacarse que las exclamaciones del último terceto

¡Oh miserable estado! ¡oh mal tamaño!
¡Que con llorarla crezca cada día
la causa y la razón porque lloraba! (v. 12-14)

admiten, gramaticalmente, la posibilidad de que el sujeto lírico se conduela, tanto por Apolo - "con llorarla » (él) - como por sí mismo - " con llorarla » (yo)-, como por ambos.

Puesto que, en términos sistémicos y si atendemos a la lógica de las varias modulaciones internas del Cancionero, cabe atender que Apolo es el prodigio de la encarnación imposible para el sujeto lírico del Soneto XI, pues Apolo quiebra la distancia que lo mantiene alejado de Dafne, figura que, sugestivamente, muchos mitógrafos individualizan como una de las ninfas.

El hermanamiento del dios solar y del sujeto lírico tiene múltiples recovecos puesto que si podemos predicar de aquél la diferencia -es el que se anima al tránsito imposible entre el yo y el otro-, encontramos, en un segundo momento, la sustancial semejanza ante el otro sexuado y distinto: el oficio de lágrimas. Lágrimas que construyen la sutil trama que escinde al yo del otro y que cifran, como signo, el dolor por esa separación; lágrimas que ejemplifican, de un modo paradójico, la pena del sujeto por saberse solo en el mismo instante en que el llanto se manifiesta como única comunicación posible a todo otro contextual.

Pues en toda lágrima anida el poder absoluto de alterar los tiempos fundiendo presente y pasado, asemejando causas y consecuencias, de modo tal que, como se nos dice en el último terceto « con llorarla crezca cada día / la causa y la razón porque lloraba » (v. 13-14). 
Que el don de lágrimas una a «Aquel que fue la causa de tal daño » (v. 9) con la voz lírica opresa en la disyuntiva del Soneto XI se ve reforzado por el rostro deficitario del olímpico que el Soneto XIII nos lega, puesto que a diferencia de las versiones canónicas de su historia en los textos clásicos, la ideación figurativa de esta composición cercena la coda consolatoria que funda, por sobre la igualdad sugerida, la radical asimetría de dioses y hombres. En aquellos Apolo se conformaba con que el laurel fuese, a posteriori, signo de triunfo en sus lides, podía -como aquí no sucede- resignificar la amargura pasada en la actualización de cada triunfo gestado en su honor, le había sido conferido -a diferencia de esta viñeta mítica- la posibilidad de entrar y salir del tiempo del dolor para recomponer la propia majestad.

Que se opte por ilustrar que el rostro de Apolo no muda y que su padecimiento se sugiere homólogo al del sujeto lírico adquiere entidad, porque la puntillosa descripción de la metamorfosis de Dafne funda el enigma que el cambio suscita: ¿sigue siendo ella, una vez vuelta en laurel? ¿Es la metamorfosis una muerte y resurrección inmediata? ¿Cómo afirmar que Dafne sigue siendo ese árbol cuya individualidad ya no se constata? ¿Cómo leer, en lo que para los parámetros de lo humano sería una ruina, el esplendor del ayer? ¿Es, acaso, posible que la pluma del autor que es signo de claridad sea, también, la de un incipiente alegorista?

A diferencia de lo que ocurre en el Soneto XI, que es pura idealización respecto de la forma absoluta y perfecta de las ninfas y absoluto vacío sobre la propia amada, el Soneto XIII se organiza desde la exhibición pormenorizada de los accidentes sufridos por las diversas partes del cuerpo femenino. Y sólo conserva, en la vertiginosa sucesión de alteraciones padecidas, el recuerdo del efecto luminoso - propio del universo de las ninfas- de esos « cabellos que el oro oscurecían » (v. 4).

Este proceso de concreción del cuerpo femenino leído a dos tiempos -por el fenómeno mismo de la metamorfosis padecida pero también como encarnación de un individuo del colectivo apostrofado en el Soneto XI- habilita un aspecto que la lejanía originaria enturbiaba: el distingo inquietante de que « los tiernos miembros » (v. 6) bajo la "áspera corteza » (v. 5) « aún bullendo estaban » (v. 6).

El texto no certifica que, míticamente, la transformación de Dafne ocurra luego de morir sino que habilita la posibilidad de que la misma subsista bajo otra forma. Y ello importa, porque el proceso de concreción y encarnación de la amada se dice abierto al distingo de interiores y exteriores, de corteza y meollos, de cuerpo y espíritu. Ella, al fin de cuentas, sigue "bullendo » (v. 6) por más que la transformación de su figura sólo sea pensable desde el detenimiento que el dios le ha impuesto al alcanzarla. Detalle final que parecería confirmar que el "mal tamaño " padecido por quienes se encuentran en análogo « miserable estado " no sería otro que el descubrir el imposible vencimiento de la interioridad del otro.

Punto crucial que impide desatender que esta derrota queda figurada, una vez más, como contienda acuosa. Lid en la cual el destino de las lágrimas 
frías y tristes que previsiblemente vierte el que cree que todo está perdido se ensombrece aún más ante la posible interpretación de que sea ese mismo dolor significado lo que le permite a la ninfa seguir, cálidamente, « bullendo ».

Llegados a este punto, finalmente, es menester formular dos aclaraciones. En primer término que el Soneto XXIX no es, en sentido recto, un soneto de metamorfosis por más que la tradición exegética haya intentado lecturas que lo afiliarían a este conjunto entendiéndolo como el relato de la aniquilación del fuego por las aguas. Y, en segundo lugar, que al no existir certeza sobre si el desenlace fue o no un castigo impuesto por la divinidad, la reescritura del motivo en el soneto garcilasiano no puede ser reintegrada al conjunto sin esta salvedad pues las otras dos composiciones son textos que plantean las metamorfosis por voluntad y no por castigo. Pero creo evidente que no resulta errada su integración a este microsistema que he intentado bosquejar puesto que las sutiles diferencias que lo apartan del diseño ideal son aquellas que permitirán recuperar otras dimensiones de análisis.

Como en el caso del mito de Apolo y Dafne, lo primero que se destaca en la narración legendaria de Hero y Leandro es un proceso de focalización y reescritura bien notorio que queda expresado en el borrado absoluto de la figura femenina, sacerdotisa que todas las noches enciende el faro para guiar al enamorado a cruzar a nado las aguas del Helesponto, al igual que la reducción de la secuencia, en su dimensión histórica, mediante la obturación de la reiteración gozosa de uniones, noche tras noche, mediante el mismo ardid.

Esta perspectiva no sólo minimiza el carácter transgresor que en las versiones originales tiene la unión de los dos amantes sino que también desdibuja la paradoja esencial en que se encuentra la doncella. Pues si es sacerdotisa debería permanecer virgen, pero al ser sacerdotisa de Venus, ¿¿debe pensarse en estado de excepción ante el imperativo que le cabe al resto de los humanos? ¿Cuál, en su circunstancia, es el mejor modo de significar respeto a la diosa? ¿Permanecer casta o no?

El Soneto XXIX nada de esto atiende porque privilegia, en notoria elección, la interacción de Leandro con las humanizadas " ondas " (v. 10) la fatídica noche en que el "viento " (v. 3) apaga la guía que la enamorada le tributa en el arriesgado y reiterado tránsito. Lo cual nos permite delinear dos tipos de peligros y una jerarquización evidente. Puesto que si para el protagonista masculino de la historia el riesgo reside en exponer el propio cuerpo a las inclemencias naturales de toda travesía a nado, el de la amada -en inestable jerarquía ante y entre los hombres y la Diosa- queda figurado como la apertura de un cuerpo que debería permanecer sellado para el otro.

Que Hero hubiese accedido a aquello que Dafne en el Soneto XIII se oponía es dato a no perder de vista ya que instala una serie de dilemas cruciales: ¿por qué la isotopía de los tránsitos que figuran la distancia entre el sujeto lírico y el otro resulta sometida, en términos míticos, a borrado por demás sugerente? ¿Por qué ante el caso notorio de una gozosa acogida del otro sexuado se recupera, 
para el canto, un tipo de figuración del peligro que sólo parecería amenazar al enamorado? ¿Por qué, ante la posibilidad de recuperar la memoria de una enamorada que accede al otro, se termina privilegiando, en la anécdota lírica, como nefando rittornello del Cancionero, a las inestables aguas tan ligadas al dolor y enfrentadas al goce?

Si partimos del parlamento final con las aguas embravecidas, podemos advertir que nuevamente se está en presencia de una coda que se figura como disyunción con la peculiaridad de que en este caso queda en evidencia que la alternativa entre el dolor y el anegamiento en el otro resulta rescrita como una oposición entre una nueva alternativa de goce vital y la posibilidad -no aplazada por las olas- de la propia muerte.

Y esto es llamativo porque la conciencia de finitud que se expresa con el « no se escusa que yo muera " (v. 12) no resulta ligada al portentoso instante mágico de la fusión sino, por el contrario, a la imposibilidad de reiterar tal prodigio. Giro que autoriza la interpretación de que el universo gozoso nunca figurado resulta jerarquizado desde la experiencia del encuentro con el otro y que ello funda -contrariamente al temor- la certeza de que la muerte no es un otro a evitar sino un destino propio. Y ello también resulta aclarado por el detalle de que la merced solicitada no resulta pautada como clemencia sino como dilación, por cuanto, según implora Leandro, el lugar idóneo de la muerte es «a la tornada » (v. 13) del goce y no antes ni en él mismo.

De donde se sigue que quizás sea esta la razón por la cual la enunciación confiere todo el protagonismo a uno de los enamorados porque lo que se quiere significar es que, ante el reconocimiento esencial y constituyente de la propia finitud, es el sendero del amor y la ilusión del otro lo que mantiene en pie y cohesionado al sujeto como tal. Razón por la cual también se puede explicar que la focalización argumental privilegie el instante del desenlace ante la duración reiterada de los encuentros previos, puesto que lo que se busca enfatizar no es la ilusión de eternidad sino el acceso feliz a la soberanía del propio tiempo: « mi vida » (v. 14).

A lo cual cabe agregar que si bien cabría especular con que el final figurado es la materialización de la metamorfosis pensada en el Soneto XI -un cuerpo que ahogándose obra la magia metafórica de "volverse agua »-, vale enfatizar que aquí no se advierte desintegración corpórea sino un entusiasmo muy otro, aún en lo sombrío de la situación, por la propia corporeidad.

Pues Leandro es cuerpo vital en el que coexisten la dignidad del esfuerzo y la miseria de la defección; cuerpo para el cual no se reserva, líricamente, metamorfosis alguna a no ser su final; cuerpo que la memoria de la fábula recupera y exalta porque el lector del Cancionero comprende -por más que su muerte no resulte figurada- que lo valioso de esa vida que se aventuró al amor y al tránsito de las aguas que de su amada lo separaban es que, " como pudo, esforzó su voz cansada" (v. 9). 
